\title{
Estimation of Far-field Coseismic Deformation Caused by the Recent Giant Earthquakes
}

\author{
Nguyen Anh Duong*, Vu Minh Tuan, Bui Van Duan, \\ Vi Van Vung, Nguyen Thuy Linh \\ Institute of Geophysics, Vietnam Academy of Science and Technology, \\ 18 Hoang Quoc Viet, Cau Giay, Hanoi, Vietnam \\ Received 17 March 2017 \\ Revised 20 April 2017; Accepted 25 May 2017
}

\begin{abstract}
In this paper, we estimate coseismic displacements in Vietnam caused by the 2004 Sumatra and the 2011 Tohoku earthquakes using static fault models in a layered spherical earth model. We find that the 2004 Sumatra earthquake caused southwestward movement of about 56 $\mathrm{mm}$ in Southern Vietnam and gradually decreasing to the north. While the 2011 Tohoku earthquake moved the area in the opposite direction, by about $0.9 \mathrm{~mm}$ to the east and about 0.4 $\mathrm{mm}$ to the north. The difference in amplitude of coseismic displacements is due to the distance from each source fault to the study area and the compact slip region of the 2011 Tohoku earthquake affected to the size of coseismic deformation area. Our results indicate that it is necessary to take into consideration of the coseismic deformation induced by the giant earthquakes on discussion of tectonic deformation in Vietnam.
\end{abstract}

Keywords: Earthquake, coseismic displacement, static fault model, Vietnam.

\section{Introduction}

In the early 21th century, two giant earthquakes occurred: the 26 December 2004 M9.1 Sumatra earthquake [1] and the 11 March 2011 M9.0 Tohoku earthquake [2]. These earthquakes occurred at about $1000 \mathrm{~km}$ and $4000 \mathrm{~km}$ distance from Vietnam, respectively, if we refer to epicenters. The 2004 Sumatra earthquake ruptured at least $1200 \mathrm{~km}$ of the megathrust along the plate boundary between the Indian - Australian plate and the Eurasian plate. Its epicenter located the southernmost end of the source region. Thus, the distance from the study area to the earthquake epicenter is shorter (about 800 $\mathrm{km})$. While, the 2011 Tohoku earthquake is the largest seismic event occurred after the 2004 Sumatra earthquake. This event occurred near the northeastern coast of Honshu Island, Japan, as a result of thrust faulting caused by the Pacific plate subduction beneath the Japan Island Arc. The fault rupture is characterized by a compact region of high-slip of about $450 \mathrm{~km}$ long and about $200 \mathrm{~km}$ wide localized near the trench with a large maximum slip up to $60 \mathrm{~m}$ [3].

\footnotetext{
*Corresponding author. Tel.: 84-912022658.

Email: duongnaigp@yahoo.com

https://doi.org/10.25073/2588-1124/vnumap.4201
} 
Based on GPS observation as well as dislocation model for a spherical body, far-field coseismic offsets produced by these earthquakes at distances thousands of kilometers away from the earthquake

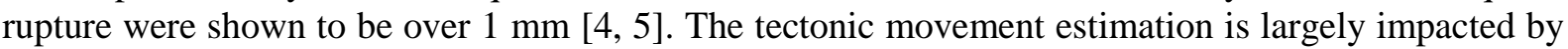
the coseismic offsets if not taking them into account. Therefore, the effect of these distant giant earthquakes must be considered to discuss crustal deformation in Vietnam where tectonic deformation rate is not high, so considering the precision requirements. In this study, the coseismic displacements induced by those earthquakes are calculated at GPS sites and seismic stations in Vietnam, serving for removing the effect of the earthquakes on the actual tectonic movement to better understand tectonic loading processes in this region.

\section{Theory}

We assume the Earth is a spherical geometry with radius R. In the epicentral coordinate system, an observation point is $\boldsymbol{R}=(R, \theta, \varphi)$, in which $\theta$ and $\varphi$ are latitude and longitude, respectively. An earthquake source has coordinates at $\boldsymbol{R} s=(R=R s, \theta=0)$. The bulk modulus and shear modulus are assumed to be laterally homogeneous, depending only on radius.

The total displacement at the observation point caused by the source is obtained as a summation of spheroidal and toroidal modes and given by

$$
s(R, \theta, \varphi)=\sum_{l} \Sigma_{m} s_{l}^{m(S)}(R, \theta, \varphi)+s_{l}^{m(T)}(R, \theta, \varphi)
$$

where $s_{l}^{m(S)}$ and $s_{l}^{m(T)}$ are for spheroidal and toroidal modes, respectively.

$$
\begin{aligned}
& s_{l}^{m(S)}(R, \theta, \varphi)=\left[y_{1}^{l m(S)}(R) \widehat{\boldsymbol{R}}+y_{3}^{l m(S)}(R) \nabla_{1}\right] Y_{l}^{m}(\theta, \varphi) \\
& s_{l}^{m(T)}(R, \theta, \varphi)=-y_{1}^{l m(T)}(R) \widehat{\boldsymbol{R}}+\nabla_{1} Y_{l}^{m}(\theta, \varphi)
\end{aligned}
$$

$\nabla_{1}$ is the surface gradient operator,

$$
\nabla_{1}=\frac{\partial}{\partial \theta} \hat{\theta}+(\sin \theta)^{-1} \frac{\partial}{\partial \varphi} \hat{\varphi}
$$

According to Edmonds [6], $Y_{l}^{m}(\theta, \varphi)$ is defined as the fully normalized spherical harmonics of total degree $l$ and azimuthal order number $m$. With positive $m$, we have therefore

$$
Y_{l}^{m}(\theta, \varphi)=(-1)^{m}\left[\frac{(2 l+1)(l-m) !}{4 \pi(l+m) !}\right]^{\frac{1}{2}} P_{l}^{m}(\cos \theta) e^{i m \varphi}
$$

where $P_{l}^{m}$ is the associated Legendre polynomial, and the first term of the asymptotic expansion of $P_{l}^{m}(\cos \theta)$ for large $l$ is given by

$$
P_{l}^{m}(\cos \theta)=(-l)^{m}\left(\frac{2}{\pi l \sin \theta}\right)^{\frac{1}{2}} \cos \left[\left(l+\frac{1}{2}\right) \theta-\frac{\pi}{2}+\frac{m \pi}{2}\right]+O\left(l^{-\frac{1}{2}}\right)
$$

where

$$
\varepsilon \leq \theta \leq \pi-\varepsilon, \quad \varepsilon>0, l \gg m, l \gg \frac{1}{\varepsilon}
$$

In particular, (5) becomes

$$
Y_{l}^{0}(\theta, \varphi)=\left[\frac{(2 l+1)}{4 \pi}\right]^{\frac{1}{2}} P_{l}(\cos \theta)
$$

Complex conjugation of $Y_{l}^{m}(\theta, \varphi)$ is

$$
Y_{l}^{-m}(\theta, \varphi)=(-1)^{m} Y_{l}^{m \varepsilon}(\theta, \varphi)
$$


The corresponding normal and shear tractions are shown

$\widehat{\boldsymbol{R}} \cdot \boldsymbol{T}_{l}^{m(S)}(R, \theta, \varphi)=\left[y_{2}^{\operatorname{lm}(S)}(R) \widehat{\boldsymbol{R}}+y_{4}^{\operatorname{lm}(S)}(R) \nabla_{1}\right] Y_{l}^{m}(\theta, \varphi)$

for spheroidal models, and

$\widehat{\boldsymbol{R}} \cdot \boldsymbol{T}_{l}^{m(T)}(R, \theta, \varphi)=-y_{2}^{l m(T)}(R) \widehat{\boldsymbol{R}}+\nabla_{1} Y_{l}^{m}(\theta, \varphi)$

for toroidal models, where $\boldsymbol{T}$ denotes the stress tensor in a isotropic medium.

\section{Modeling}

Along with technological development in instrumentation as well as data analysis software, GPS has become a common tool for geophysical investigation in 1990's. In Vietnam, the first geodetic network of 16 GPS sites covering Red River fault zone was installed in 1994 to obtain their precise coordinates and their temporal changes [7]. Many GPS sites in Vietnam have been continually observed since then [8], thereby their velocities are considered to be free from the effect of seasonal and long period noise [9]. On the other hand, the impact of the far-field coseismic displacements caused by the 2004 Sumatra and the 2011 Tohoku earthquakes may be significant. So we estimate displacements caused by these earthquakes at the GPS sites using static fault models of these earthquakes.

Many distant IGS sites throughout the Southeast Asia recorded a measurable coseismic signal of the 2004 Sumatra earthquake. Chlieh et al. [10] distinguished between far-field $(300-1100 \mathrm{~km})$ and very-far-field $(>1100 \mathrm{~km})$ data because the effect of the Earth's stratification and sphericity becomes significant typically beyond about $1100 \mathrm{~km}$ [4]. Similarly, Shestakov et al. [11] recognized that the predicted offset magnitudes underestimated by a factor of 1.5-2 at the far-field sites without adopting of the spherically layered isotropic medium approach.

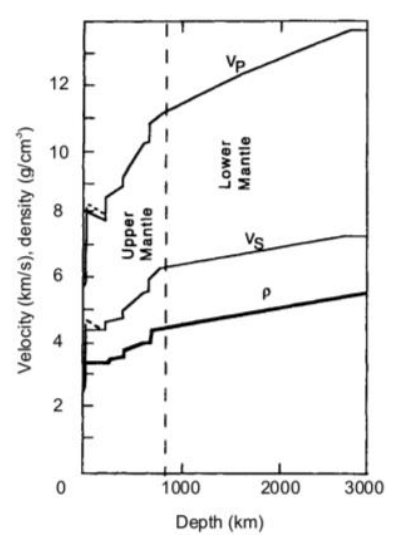

Fig. 1. The Preliminary Reference Earth Model (PREM) of P velocity (Vp), S velocity (Vs), and density ( $\rho)$ as a function of depth (up to lower Mantle) in the Earth. Dashed lines are the horizontal components of velocity.

All different seismic wave types have been analyzed in detetermining Earth structure, ranging from free body waves reflected from shallow sedimentary layers. The waves reveal aspects of the Earth incorporated in Earth models, functional descriptions of how the material properties vary in the interior. The Preliminary Reference Earth Model (PREM) [12] was constructed to model a large number of body wave travel times, free-oscillation eigenfrequences, and surface wave and normal 
attenuation measurements. We assume physical properties for each layer of the spherical earth model based on PREM that is shown in Fig. 1.

As for the source fault model, a large amount of models has been suggested for the 2004 Sumatra earthquake $[4,13]$ and the 2011 Tohoku earthquake $[5,14]$ based on the geodetic, seismic waves, ocean-bottom pressure gauges and tsunami waveform data. The models more or less adequately explain coseismic displacements observed in the near-field zone. Only few studies computed coseismic displacements from their models were then compared with the observed ones at a sparse GPS network of far-field sites [4, 5, 13]. Applying a different fault model naturally gives different coseismic deformations. In this study, we apply the proper source fault model that is available digital data of rupture size and slip distribution; moreover, utilize the observed coseismic displacements at far-field GPS sites to compare with the predicted ones.

In order to choose a proper fault slip model of the 2011 Tohoku earthquake, Zhou et al. [15] selected the fault models inverted from different data (seismic waves and combination of seismic and geodetic data) and then compared the predicted coseismic displacements based on the models with the observed data in Japan and China. Results, no significant differences exist in far-field displacements among the models. Moreover, the model constrained by GPS data fits GPS displacements better than other's not. Thus, we use a rupture model D of Kreemer et al. [13] for the 2004 Sumatra earthquake. The rupture model was inferred from the far-field continuous GPS data. In contrast to the Sumatra region, a huge set of GPS data from GPS Earth Observation Network (GEONET) was used by different organizations and researchers for updating the source model of this seismic event $[5,14]$. Finally, we utilize a model of Gusman et al. [14] for the 2011 Tohoku earthquake. The rupture model was inverted from tsunami waveforms, GPS data, and seafloor crustal deformation data. The simulated tsunami waveforms from the source model fit well with the observed ones at Deep-ocean Assessment and Reporting of Tsunamis (DART) buoys that are located offshore and across the Pacific Ocean. Some of buoys can be considered as far-field even very far-field sites from the epicenter.

\section{Results and discussion}

We predict the coseismic displacements induced by the 2004 Sumatra event at 27 GPS sites in Southeast Asia and adjacency, and then compare with the observed ones (GPS-derived ones) at the same sites. The predicted coseismic displacements are shown in Fig. 2 together with Kreemer et al.'s observed ones [13]. The Fig. 2 exhibits a similar pattern of the predicted and observed coseismic displacements.

For the 2011 Tohoku earthquake, we predict the coseismic displacements at five far-field IGS sites (DAEJ, SHAO, WUHN, IRKT, and KUNM) located along the direction from the epicenter to the study area, using the rupture model of Gusman et al. [14]. The predicted result is shown in Table 1. In order to have the observed coseismic displacements at the IGS sites, we analyze GPS coordinate - time series observed at those IGS sites during 30 days before and after of March 11, 2011 (time occurrence of the 2011 Tohoku earthquake) (Fig. 3). Then, we estimate the observed coseismic offsets caused by the 2011 Tohoku earthquake (Table 1). It clearly shows the large coseismic offsets at the sites close to the epicenter.

In order to estimate how the predicted coseismic displacements agree with the observed ones, we use the root mean square (RMS) error to measure the differences between them by the following formula:

$$
\text { RMS errors }=\sqrt{\frac{1}{N} \sum_{i=1}^{N}\left(\mathrm{u}_{\text {observed }}^{i}-u_{\text {predicted }}^{i}\right)^{2}}
$$


The RMS errors are reported in Table 2. The differences between the predicted and observed displacements caused by the 2004 Sumatra earthquake are $2.2 \mathrm{~mm}$ for east component and $1.9 \mathrm{~mm}$ for north component. This result shows that our predicted coseismic displacements compare favorably with the observed ones of Kreemer et al. [13].

For coseismic displacements induced by the 2011 Tohoku earthquake, the RMS error of east component $(4.0 \mathrm{~mm})$ is high abnormally compared with that of north component $(0.7 \mathrm{~mm})$ due to DAEJ site (Table 3). DAEJ site is located about $1300 \mathrm{~km}$ west of the epicenter and perpendicular to the subducting slab so that the coseismic and postseismic slip is heavily influenced from the event. Fig. 3 (east component of DAEJ) shows that the coseismic offset is overestimated due to effect of postseismic slip that more clearly appeared after about two weeks at this site. If the RMS error is calculated without DAEJ, its horizontal component will be only $1.0 \mathrm{~mm}$. It is no significant difference between the predicted and observed coseismic displacements. Thus, the results imply that both numerical rupture models of earthquakes adequately explain the far-field coseismic displacements in Vietnam.

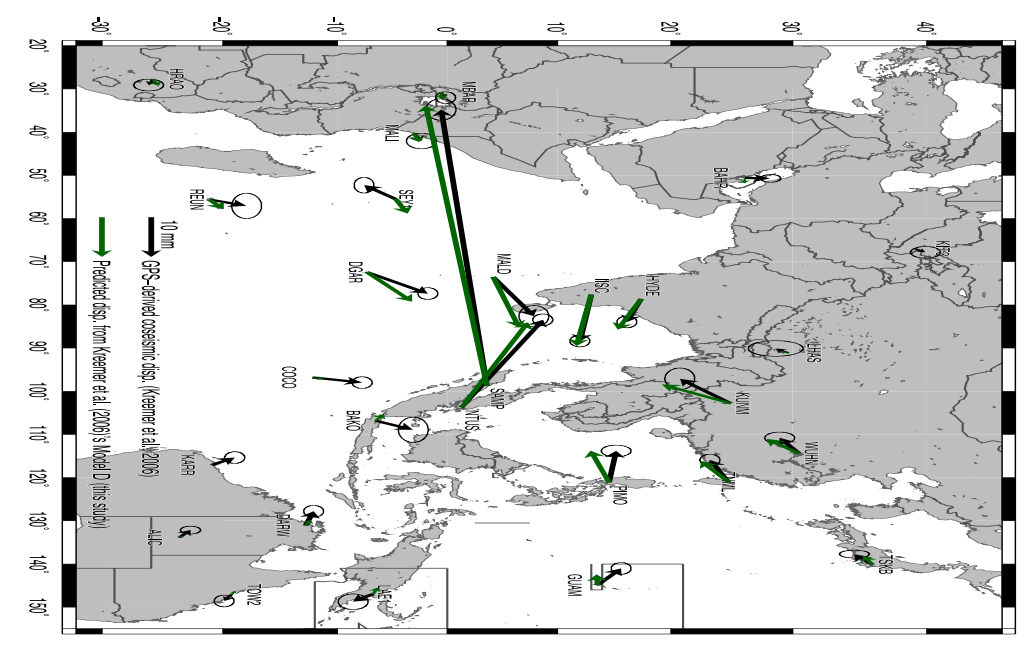

Fig. 2. Coseismic displacements caused by the 2004 Sumatra earthquake. Observed coseismic displacements [13] and predicted displacements in this study. Uncertainties in observed vectors are shown as 95\% confidence ellipses. The dashed displacements for station SAMP are plotted at half the scale as the other vectors.

Table 1. Predicted and GPS-derived coseismic displacements caused by the 2011 Tohoku earthquake in five IGS sites.

\begin{tabular}{|c|c|c|c|c|c|c|c|c|c|c|}
\hline \multirow{3}{*}{ Site } & \multirow{3}{*}{ Lon. $\left({ }^{\circ} \mathrm{E}\right)$} & \multirow{3}{*}{ Lat. $\left({ }^{\circ} \mathrm{N}\right)$} & \multirow{3}{*}{$\begin{array}{l}\mathrm{D} \\
(\mathrm{km})\end{array}$} & \multirow{3}{*}{$\begin{array}{l}\text { Azi. } \\
\left({ }^{\circ}\right)\end{array}$} & \multicolumn{2}{|c|}{ Predicted } & \multicolumn{4}{|c|}{ GPS-derived } \\
\hline & & & & & $\Delta_{\text {east }}$ & $\Delta_{\text {north }}$ & $\Delta_{\text {east }}$ & $\Delta_{\text {north }}$ & $\sigma_{\text {east }}$ & $\sigma_{\text {north }}$ \\
\hline & & & & & $\overline{(\mathrm{mm})}$ & $(\mathrm{mm})$ & $(\mathrm{mm})$ & $(\mathrm{mm})$ & $(\mathrm{mm})$ & $(\mathrm{mm})$ \\
\hline DAEJ & 127.37 & 36.39 & 1332 & 77 & 16.4 & 2.7 & 25.3 & 2.4 & 2.1 & 1.2 \\
\hline SHAO & 121.20 & 31.09 & 2103 & 62 & 5.2 & 1.6 & 5.4 & 1.1 & 1.3 & 1.2 \\
\hline WUHN & 114.35 & 30.53 & 2698 & 64 & 3.2 & 1.1 & 3.1 & 0.0 & 1.2 & 1.0 \\
\hline IRKT & 104.31 & 52.21 & 3306 & 102 & 2.8 & -0.5 & 3.3 & -0.3 & 1.5 & 2.1 \\
\hline KUNM & 102.79 & 25.02 & 3987 & 59 & 1.5 & 0.6 & 0.3 & -0.3 & 1.5 & 0.9 \\
\hline
\end{tabular}

(D: distance from site to epicenter; Azi.: azimuth of site to epicenter is clockwise from the north) 
Table 2. The differences between the predicted and observed displacements caused by the 2004 Sumatra and the 2011 Tohoku earthquakes.

\begin{tabular}{lllll}
\hline \multirow{2}{*}{ Coseismic offsets from } & \multicolumn{2}{l}{ RMS errors $(\mathrm{mm})$} & Remark \\
\cline { 2 - 5 } & East & North & Horizontal & \\
\hline The 2004 Sumatra EQ. & 2.2 & 1.9 & 2.9 & - \\
\multirow{2}{*}{ The 2011 Tohoku EQ. } & 4.0 & 0.7 & 4.1 & with DAEJ \\
& 0.7 & 0.7 & 1.0 & without DAEJ \\
\hline
\end{tabular}
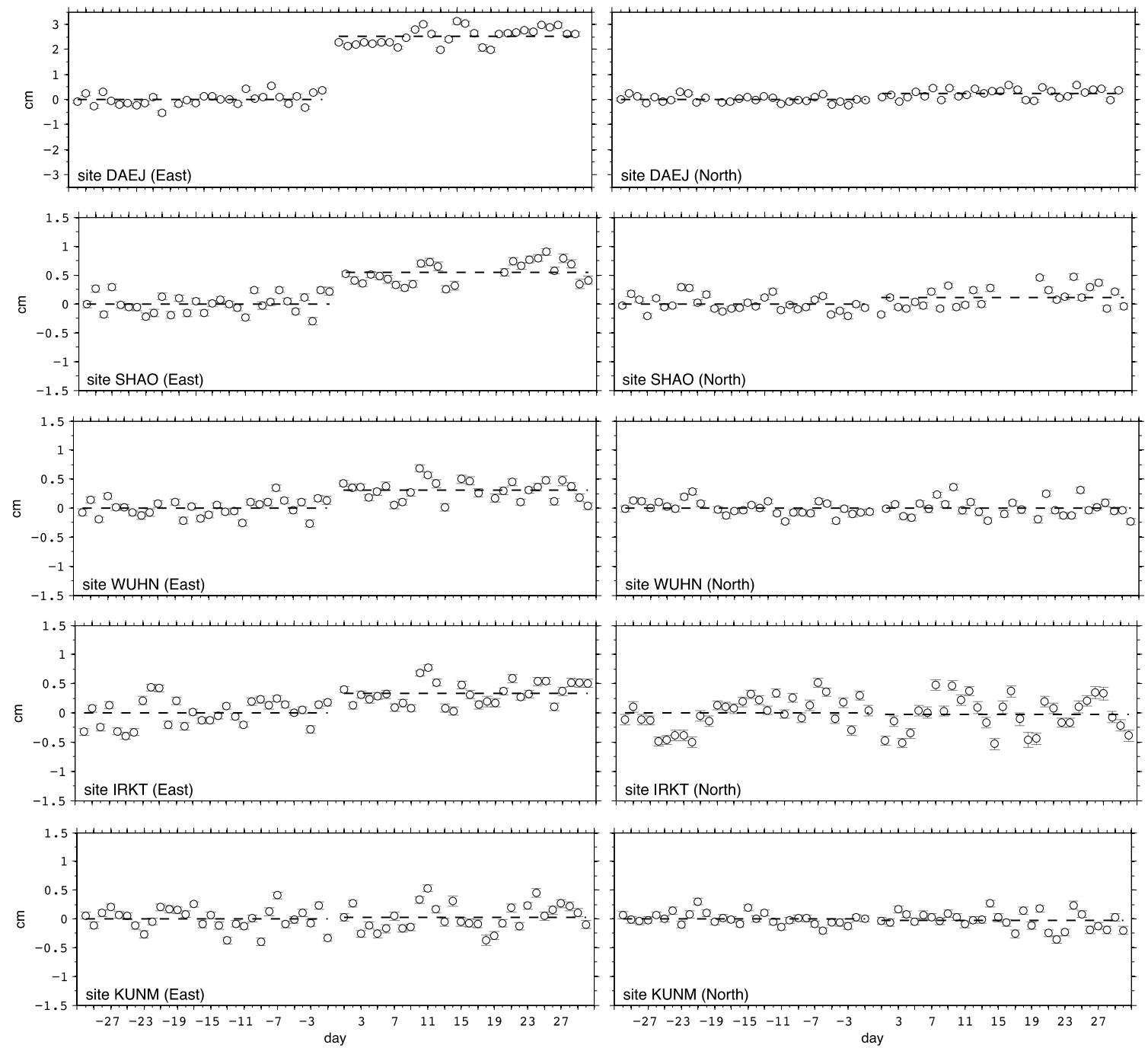

Fig. 3. Time-series of east and north components of the daily positions for five IGS sites. Days are relative to March 11, 2011 (day 0). Error-bars are formal 1-sigma uncertainties. Time-series have been detrended using the secular station velocity, and are shown here relative to the average position (dashed line) of the 30 days before March 11, 2011. The average position (dashed line) of the 30 days after the earthquake is indicated as well. 


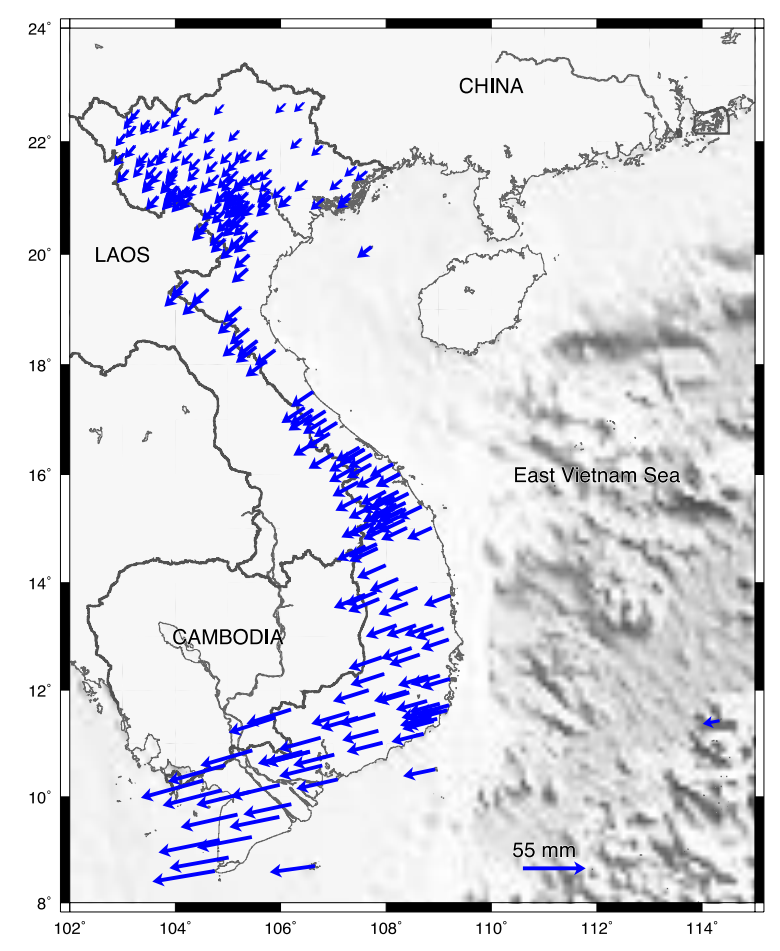

Fig. 4. The predicted horizontal far-field coseismic displacements caused by the 2004 Sumatra earthquake at the GPS sites in Vietnam.

We estimate far-field coseismic offsets at GPS sites in Vietnam caused by the 2004 Sumatra and the 2011 Tohoku earthquakes using the respective fault models. Predicted horizontal displacements show that the 2004 Sumatra earthquake caused southwestward movements by about $15 \mathrm{~mm}$ in Northern Vietnam and $56 \mathrm{~mm}$ in Southern Vietnam. Meanwhile, the 2011 Tohoku earthquake produced displacements in the opposite directions, approximately $0.9 \mathrm{~mm}$ to the east and $0.4 \mathrm{~mm}$ to the north, in the study area. The difference in amplitude of coseismic displacements can be attributed to the distance from each source fault to the study area. It also demonstrates that the compact slip region of the 2011 Tohoku earthquake affected to the size of coseismic deformation area. According to previous studies, the region covering the measurable coseismic displacements caused the 2011 Tohoku earthquake is smaller than that affected by the 2004 Sumatra earthquake. Pollitz et al. [5] presented coseismic offsets of $\sim 3-5 \mathrm{~mm}$ at distances as far as 3000 to $4000 \mathrm{~km}$ from the rupture of the 2011 Tohoku earthquake. Meanwhile, coseismic displacements of 5-10 mm were detected at GPS sites located more than $3000 \mathrm{~km}$ away from the 2004 Sumatra earthquake epicenter [4, 13]. The results of the 2004 Sumatra earthquake are plotted in Fig. 4. More information can be found in the electronic supplement of this paper.

\section{Conclusions}

The results of this research provide a database of coseismic deformations induced by the recent giant earthquakes, the 2004 Sumatra and 2011 Tohoku earthquakes, at the available GPS sites in Vietnam, based on static fault models of these earthquakes in a layered spherical earth model, for developing capabilities to detect offsets in GPS coordinate time series. By the comparing between the predicted and observed offsets at GPS sites, we find that the rupture models of two earthquakes 
adequately estimate the coseismic deformation in Vietnam. As a result, the coseismic displacements caused by the 2011 Tohoku earthquake is smaller than those induced by the 2004 Sumatra earthquake in Vietnam. The difference in amplitude of coseismic displacements is due to the distance from each source fault to the study area and the compact slip region of the 2011 Tohoku earthquake affected to the size of coseismic deformation area. From this study, it is indicated that it is necessary to take into account the coseismic deformation induced by the recent giant earthquakes on discussion of tectonic deformation in Vietnam.

\section{Acknowledgments}

We would like to thank the reviewers for their helpful comments and suggestions. The current work was financially supported by Vietnam Academy of Science and Technology under the research grant VAST.DLT 10/15-16.

\section{References}

[1] Lay T., Kanamori H., Ammon C. J., Nettles M., Ward S. N., Aster R. C., Beck S. L., Bilek S. L., Brudzinski M. R., Butler R., DeShon H. R., Ekström G., Satake K., Sipkin S., The Great Sumatra-Andaman Earthquake of 26 December 2004, Science, 308 (5725), 1127-1133, 2005

[2] Simons M., Minson S. E., Sladen A., Ortega F., Jiang J., Owen S. E., Meng L., Ampuero J.-P., Wei S., Chu R., Helmberger D. V., Kanamori H., Hetland E., Moore A. W., and Webb F. H., The 2011 Magnitude 9.0 TohokuOki Earthquake: Mosaicking the Megathrust from Seconds to Centuries, Science, 332 (6036), 1421-1425, 2011.

[3] Ito T., K. Ozawa, T. Watanabe, and T. Sagiya, Slip distribution of the 2011 off the Pacific coast of Tohoku Earthquake inferred from geodetic data, Earth Planets Space, 63, 627-630, 2011.

[4] Banerjee, P., F. F. Pollitz, and R. Burgmann, The size and duration of the Sumatra-Andaman earthquake from far-field static offsets, Science, 308, 1769-1772, 2005.

[5] Pollitz, F., Bürgmann R., and Banerjee P., Geodetic slip model of the 2011 M9.0 Tohoku earthquake, Geophys. Res. Lett., 38, L00G08, 2011.

[6] Edmonds, A.R., Angular momentum in quantum mechanics, Princeton University Press, Princeton, NJ, 1960.

[7] Tran Dinh To, Nguyen T. Y., Duong C. C., Vy Q. H., Zuchiewicz W., Cuong N. Q., Nghia N. V., Recent crustal movements of northern Vietnam from GPS data, J. Geodyn., 69, 5-10, 2013.

[8] Nguyen Anh Duong, T. Sagiya, F. Kimata, D. T. Tran, Q. H. Vy, C. C. Duong, X. B. Nguyen, and D. X. Nguyen, Contemporary horizontal crustal movement estimation for northwestern Vietnam inferred from repeated GPS measurements, Earth Planets Space, 65(12), 1399-1410, 2013.

[9] Blewitt, G. and D. Lavallée, Effect of annual signals on geodetic velocity, J. Geophys. Res., 107(B7), $2145,2002$.

[10] Chlieh M., et al., Coseismic slip and afterslip of the great M-w 9.15 Sumatra-Andaman earthquake of 2004. Bulletin of the Seismological Society of America, 97(1), p. S152-S173, 2007.

[11] Shestakov N. V., H. Takahashi, M. Ohzono, A. S. Prytkov, V. G. Bykov, M. D. Gerasimenko, M. N. Luneva, G. N. Gerasimov, A. G. Kolomiets, V. A. Bormotov, N. F. Vasilenko, J. Baek, P.-H. Park, and M. A. Serov, Analysis of the far-field crustal displacements caused by the 2011 great Tohoku earthquake inferred from continuous GPS observations. Tectonophysics, 524- 525, 76-86, 2012.

[12] Dziewonski A. M. and Anderson D. L., Preliminary reference Earth model, Physics of the Earth and Planetary Interiors, 25, 297-356, 1981.

[13] Kreemer C., Blewitt G., Hammond W.C., and Plag H. P., Global deformation from the great 2004 SumatraAndaman Earthquake observed by GPS: Implications for rupture process and global reference frame, Earth Planets Space, 58, 141-148, 2006.

[14] Gusman A. R., Tanioka Y., Sakai S., Tsushima H., Source model of the great 2011 Tohoku earthquake estimated from tsunami waveforms and crustal deformation data, Earth and Planetary Science Letters, 341, 234-242, 2012.

[15] Zhou X, Sun W, Zhao B, Fu G, Dong J, Nie Z (2012) Geodetic observations detecting coseismic displacements and gravity changes caused by the $\mathrm{Mw}=9.0$ Tohoku-Oki earthquake. J Geophys Res., 117:B05408, 2012. 